\title{
Nota sobre la introducción de la fenomenología de Merleau-Ponty en la Argentina. La importancia de la Estética de Guerrero
}

Recibido el 14/og/2020. Aceptado el 22/11/2020.

\begin{abstract}
Resumen
El artículo comienza con una breve referencia a la introducción de la fenomenología de Merleau-Ponty en la Argentina. Se consideran primero las contribuciones de Luis M. Ravagnan y Carlos L. Ceriotto para pasar luego a un examen de las referencias efectuadas por Luis Juan Guerrero en su Estética. En relación con la estética de las manifestaciones artísticas se pone énfasis en la noción merleau-pontyana de lenguaje indirecto y en la significación de las voces del silencio. En lo que concierne a la estética de las potencias artísticas se pone el acento en la experiencia no-objetiva de convivencia en la comprensión mutua, a fin de dar cuenta de la respuesta del artista al llamado de la tradición cultural y de la respuesta del espectador al llamado de la obra de arte. Finalmente, respecto del problema de las tareas artísticas, la atención se focaliza en el análisis que Guerrero, nuevamente siguiendo a Merleau-Ponty, ofrece sobre las fiestas cuyo rasgo distintivo es ser el gran juego de pueblos históricos y el lugar originario de reunión de todas sus tareas artísticas.
\end{abstract}

Palabras clave: lenguaje indirecto, manifestaciones artísticas, potencias artísticas, tareas artísticas.

\section{Note on the introduction of Merleau-Ponty's phenomenology in Argentina. The importance of Guerrero's Estética}

\begin{abstract}
The paper begins with a brief account of the introduction of Merleau-Ponty's phenomenology in Argentina. It first mentions the contributions of Luis M. Ravagnan and Carlos L. Ceriotto and then goes on to examine the references made by Luis Juan Guerrero in his Aesthetics. As regards the aesthetics of artistic manifestations, emphasis is laid on Merleau-Ponty's notion of indirect language and the significance of the voices of silence. With reference to the aesthetics of artistic powers, the non-objective experience of living together in a reciprocal understanding is highlighted in order to account for the answer of the artist to the call of the cultural tradition and the answer of a spectator to the call of the work of art. Finally,
\end{abstract}


regarding the issue of aesthetic tasks, attention is focused on the analysis which Guerrero, again following Merleau-Ponty, offers on festivals whose distinctive trait is to be the great play of historical peoples and the originary place that gathers all their artistic tasks.

Keywords: Indirect language, Artistic manifestations, Artistic powers, Artistic tasks.

En la introducción del pensamiento de Merleau-Ponty en nuestro país tienen importancia en el terreno estrictamente filosófico las referencias de Luis Juan Guerrero en la obra Estética operatoria en sus tres direcciones. Sin embargo, esta época inicial contiene también otras expresiones de interés por el fenomenólogo francés previas y paralelas, principalmente en relación con la psicología y el psicoanálisis. Señalaré, sucintamente, en primer lugar, algunas de estas menciones a la obra de Merleau-Ponty hasta 1970, antes de ocuparme, luego, de la primera elaboración filosófica del pensamiento del fenomenólogo francés que aparece en la Estética de Guerrero, a través del tema del lenguaje indirecto y las voces del silencio.

La primera mención documentada de Merleau-Ponty que he encontrado es la referencia de Gaston Berger en la sesión del 4 al 6 de abril de 1949 de la sección "Filosofía de la existencia", en el notable Primer Congreso Nacional de Filosofía que se celebró en Mendoza en 1949. Es una alusión a "la experiencia, toda temporal, del acuerdo del hombre 'con sí mismo y con el otro' (Merleau-Ponty)" (Berger 1950: II, 968). Se lo menciona, junto con otros pensadores franceses y Heidegger, en una reflexión sobre el compromiso con el tiempo y los problemas de la época.

Una inclusión de obras de Merleau-Ponty en los programas de la carrera de Psicología de la Facultad de Filosofía y Letras de la Universidad de Buenos Aires se encuentra en la bibliografía del programa de Psicología I, presentado en 1952 por el profesor Luis María Ravagnan, quien se desempeñó como profesor titular desde 1949 hasta 1957. Luego pasó a ser profesor, y en 1964 Director del Departamento de Psicología de la Facultad de Humanidades y Ciencias de la Educación de la Universidad Nacional de La Plata. La actividad docente estuvo acompañada de publicaciones.

En 1952 Ravagnan publica, en Monografías psicológicas de la Universidad de Buenos Aires, su trabajo La unidad psicofísica en el que se ocupa del problema del cuerpo en el marco de la fenomenología con referencias a Merleau-Ponty. Le siguen menciones en artículos en el ámbito de la psicología, a los cuales se añaden, en la Revista de Educación de la Universidad Nacional de La Plata, la reseña "Maurice Merleau-Ponty: La Structure du comportement" (1957), y el artículo "Acerca del esquema corporal" (1958), basado en la Fenomenología de la percepción, y, en el diario La Nación, el artículo "Merleau-Ponty y la psicología fenomenológica" (1959). En el libro Problemas psicológicos contemporáneos (1958) se incluye un capítulo sobre "El cuerpo y la sexualidad: el enfoque fenomenológico de Merleau-Ponty". En 1967, publica, en una serie integrada por libros breves dedicados a la presentación de numerosos pensadores, la obra Merleau-Ponty (1967), que se compone de un "Estudio preliminar" y una selección de textos de La estructura del comportamiento, la Fenomenología de la percepción, Sentido y sin-sentido, Signos y Las aventuras de la dialéctica. El "Estudio preliminar" consiste en una exposición general de MerleauPonty, quien es presentado como "la expresión de una filosofía auténtica, abierta a infinitas trayectorias" y el autor de una "densa obra que se lee y relee, brindando en cada lectura nuevos descubrimientos, en tanto late ante nuestros ojos como objeto de permanente y reiterada meditación" (Ravagnan 1967: 5). Con posterioridad aparecen las obras Psicología existencial (1969), y La psicología fenomenológica: Maurice Merleau-Ponty (1974). 
En la carrera de Filosofía, a fines de la década del 6o, Eugenio Pucciarelli incluía el tema de la corporalidad en Merleau-Ponty en sus cursos de Gnoseología y Metafísica. En 1966 defendí una tesis de licenciatura sobre "Merleau-Ponty, filósofo del lenguaje". A ello se sumó el artículo "Merleau-Ponty y el problema del tiempo" (1970). Mi interés inicial por la obra de Merleau-Ponty fue motivada por la publicación en 1957 de la traducción de La estructura del comportamiento en la Biblioteca Hachette de Filosofía dirigida por Gregorio Weinberg.

En 1964, Carlos Ludovico Ceriotto (1928-1973), profesor titular en la Facultad de Filosofía y Letras de la Universidad Nacional de Cuyo desde 1960, publica el artículo "Lenguaje y reflexión según Merleau-Ponty" (Philosophia, Mendoza, Universidad Nacional de Cuyo, Facultad de Filosofía y Letras, $\mathrm{N}^{\circ} 14$ ). Le sigue en 1969 su obra Fenomenología y psicoanálisis, que se compone de capítulos dedicados a Jean-Paul Sartre, Merleau-Ponty, Alphonse De Waelhens y Paul Ricoeur.

En el capítulo sobre nuestro pensador se presenta un "marco $u$ horizonte dentro del cual habrá que examinar el psicoanálisis de Freud" (Ceriotto 1969: 73). Se destacan los puntos de vista de Merleau-Ponty sobre la significación del psicoanálisis en el descubrimiento de funciones que se creían puramente corporales, la transformación de la noción de instinto, la imposibilidad de persistir en una imagen dicotómica del hombre, y la necesidad de liberar el psicoanálisis del cientificismo y el objetivismo poniendo de relieve, más allá de las limitaciones de Freud, que es una manera de entender al hombre y la cultura. Luego de examinar textos de La estructura del comportamiento, Fenomenología de la Percepción y Signos con el objetivo de mostrar que la función de la fenomenología es evitar contradicciones en el psicoanálisis, Ceriotto se detiene, como "último texto de Merleau-Ponty que vamos a examinar", en el prefacio escrito para una obra de A. Hesnard. Y reproduce las afirmaciones de que "el psicoanálisis está lleno de un pensamiento que no se expresa sino muy indirectamente en ciertos conceptos freudianos" y de que fenomenología y psicoanálisis "se dirigen ambos hacia la misma latencia" (Merleau-Ponty, 2000: 277, 283). En relación con la expresión indirecta, y con referencia al reemplazo de metáforas energéticas por metáforas estructurales, ya se había afirmado con una cita de Merleau-Ponty que "no hay lenguaje más preciso y riguroso que la metáfora, única capaz de 'sacudir el aparejo del lenguaje para arrancarle un sonido nuevo'" (Merleau-Ponty, 2000: 92).

La cita pertenece a un pasaje de "El lenguaje indirecto y las voces del silencio" que termina con estas palabras: "Comencemos por comprender que hay un lenguaje tácito y que la pintura habla a su manera" (Merleau-Ponty, 1960: 58 s.). Explicitar este tema ha sido una cuestión central en la estética de Guerrero.

Luis Juan Guerrero nació en 1899 , hizo sus estudios universitarios en Suiza, y se graduó de doctor en filosofía en la Universidad de Zürich en 1925 con la tesis Die Entstehung einer allgemeinen Wertlehre in der Philosophie der Gegenwart [El origen de una axiología general en la filosofía contemporánea], que se publicó en Marburgo en 1927. Fue profesor de Estética y Ética en las universidades de La Plata, del Litoral y de Buenos Aires. Falleció en 1957. Su obra principal es Estética operatoria en sus tres direcciones.

En las páginas iniciales del "Prólogo", Guerrero escribe:

La metodología inaugurada por Husserl y consumada por Heidegger, especialmente en los últimos aportes de ambos pensadores, nos da una base firme para la exposición de los problemas. Algunos esquemas ónticos y muchas sugestiones valiosas tienen sus fuentes en los finos razonamientos de Souriau, 
el sabio pensamiento clásico de Helmut Kuhn, las intransigencias de Sartre, la comprensiva penetración de Merleau-Ponty, los intentos desperdigados de Fritz Kaufmann y el impresionismo deslumbrante de Malraux (Guerrero, 1956a: 13 ss.).

La "comprensiva penetración" de Merleau-Ponty está presente reiteradamente en las tres partes de la obra. En primer lugar, la estética ha de operar como "filosofía primera" a fin de hacer posible la constitución de disciplinas particulares o filosofías segundas como las ciencias del arte, las tradicionales historias del arte, las investigaciones psicológicas y sociológicas sobre el arte, etc. En segundo lugar, la estética ha de operar en el seno de la creación artística transfigurando con su poder interpretativo la actividad creadora que ella estudia. En tercer lugar, la estética ha de operar en el dominio de las doctrinas del arte de todas las épocas de la historia y de todas las regiones de la tierra. Se han de constituir estéticas regionales dentro de los criterios operatorios de un universalismo estético a la vez unificador y pluralizador. En cada dirección de la estética se formulan las articulaciones de la revelación y el acogimiento, de la creación y la ejecución, y de la promoción y requerimiento. El ser humano acoge, produce y fomenta mediante la obra de arte un ámbito de sentido. Y la obra de arte se muestra como ente contemplable o conjunto de indicaciones para una acogedora revelación, como proceso en trance de una gestación que logra constituirla como tal, y como una estructura de cumplimiento o realización que responde a propuestas, sugerencias o demandas de la comunidad.

En la estética de las manifestaciones artísticas se analiza el modo en que el hombre acoge una obra de arte, es decir, la hace acontecer. La significación global de una obra se encuentra en estado de potencia o virtualidad, y se actualiza cuando la invitación que ofrece a la existencia humana encuentra una respuesta. Un significado se constituye en el momento en que se produce un acuerdo o pacto entre la solicitud de la obra y la acogida del espectador, esto es, una connivencia entre el llamado de la obra y la acogida del espectador. En este contexto, Guerrero afirma que "el ensayo de M. Merleau-Ponty, 'El lenguaje indirecto y las voces del silencio' tiene una importancia capital para los problemas del significado estético" (Guerrero, 1956a: 189). Y recuerda que MerleauPonty ha comparado al escritor con el tejido que trabaja por el revés desarrollando el lenguaje por caminos oblicuos porque las palabras nunca señalan de una manera unívoca y directa. Al ocuparse de la trama de los significados y subrayar que las artes no elaboran sus significados con procedimientos rectilíneos y convencionales como ocurre con el empleo de signos, señales e instrumentos en la vida cotidiana, Guerrero recurre a la siguiente y extensa cita de ese trabajo (Guerrero, 1956a: 165 s.):

Una novela se expresa tácitamente como un cuadro. Se puede narrar el tema de una novela como el de un cuadro. Pero lo que cuenta, no es tanto que Julián Sorel, al saber que ha sido traicionado por Mme. de Rênal, vaya a Verrières y trate de matarla. Es, después de la noticia, ese silencio, ese viaje de sueño, esa certidumbre sin pensamientos, esa resolución eterna. No hay necesidad de un 'Julián pensaba' o un 'Julián quería'. Es suficiente, para expresarlo, que Stendhal se deslice en Julián y haga aparecer bajo nuestros ojos, con la velocidad del viaje, los objetos, los obstáculos, los medios, los azares. Es suficiente que se decida a contar en una página, en vez de contar en cinco. Esa brevedad, esa proporción inusitada entre las cosas omitidas y las cosas dichas, no resulta siquiera de una 'elección'. Consultando su propia sensibilidad con la del otro, Stendhal le ha encontrado enseguida un cuerpo imaginario más ágil que su propio cuerpo, ha hecho como en una segunda vida el viaje a Verrières, según la cadencia de pasión seca que elegiría para él lo visible y lo invisible, lo que debe decir y lo que debe callar. La voluntad de muerte para nada está en las palabras: está entre las palabras, en los intersticios de espacio, de tiempo, de significación que delimitan (Merleau-Ponty, 1960, 95). 
Comentando el pasaje, Guerrero observa que también el pintor con su contemplador, el músico con su oyente, y todo hombre con todo otro hombre mantienen un lenguaje de iniciados, es decir, de iniciados en el mundo de los imaginarios o universo de todas las posibilidades que pueden caber bajo la vida humana. El trato más elemental con los significados estéticos nos envuelve en una compleja trama de significados casi siempre alusivos o indirectos. Son "menciones laterales que van edificando los contextos cada vez más amplios de una novela, una sinfonía, un templo o una estatua" (Guerrero, 1956a: 164).

El artista presupone la previa consonancia y conmoción del sentido, la capacidad de estar a tono con algo. El procedimiento específico o auténticamente artístico, consiste en sugerir nociones y referencias que no apuntan de una manera directa y expresa al complejo significativo. La obra no dice nada de una manera directa, no necesita decirnos nada. Hace surgir frente a nosotros una perspectiva del mundo y va proyectando sus entes sobre un fondo de sentido. Esos entes cobran relieve y adquieren significación por una promoción que los eleva hasta constituir un universo total y coherente, es decir, una revelación de sentido a través de un tejido de significaciones. Lo que el artista tiene que decir ya lo supone sabido. Si el autor es un verdadero escritor que encuentra las alusiones y los saltos que jalonan una conducta, el lector responderá a su llamado y se unirá con él en el centro virtual de la obra. Autor y lector se unirán en el sentido total aunque uno y otro no lo conozcan consciente y deliberadamente. Por eso hay una simple relación de homonimia entre una novela entendida como un inventario de acontecimientos 0 enunciado de ideas, tesis, etc., y la novela como operación dentro de un estilo. Solo hay homonimia entre la novela como significado manifiesto o prosaico y la novela como significado indirecto o latente.

Guerrero critica la concepción instrumental de las palabras en la prosa porque ellas transportan al que habla o escribe, y al que lee o escucha, a un universo común, capacitándolos para nuevos significados mediante una potencia de designación que excede en mucho a la definición recibida. Así, la prosa tiene también una dimensión de poesía porque ella instaura a su manera el poder nominador de la palabra. Por eso Merleau-Ponty habla de esa "vida sorda que las palabras llevan y continúan llevando en nosotros".

Nuestro encuentro con la obra de arte se produce sobre un fondo de concordancia o consentimiento que define la situación estética inicial. Hay una mutua implicación de presencia y llamado en la obra de arte. Guerrero señala que algo similar ocurre en la percepción cotidiana. Remite a Merleau-Ponty (cfr. Merleau-Ponty, 1945: 64, 358 ss., 367 ss.), y su análisis de la cosa percibida según la cual la presencia perceptiva de la cosa es la unidad que ella nos revela como una especie de "estilo común" de las propiedades. Para Merleau-Ponty, la unidad de la cosa es "este único acento" que se reencuentra en todas las propiedades, "esta única manera de existir de la que ellas son una expresión segunda" (Merleau-Ponty, 1945: 368). Por su parte, Guerrero se refiere a la norma común a todas las cualidades significativas en la obra de arte. La diferencia reside en que con la obra de arte no efectuamos una lenta y paciente exploración perceptiva sino que ella ejerce una imposición sobre nosotros. La obra de arte tiene una manera impositiva o impulsiva de presentarse por sí misma, y ella implica una solicitud o llamado. Tiene una estructura normativa que nos impone una manera de ver, oír, comprender, etc. hace un llamado a todo nuestro ser para que cumpla la respuesta correspondiente. Otro tema que Guerrero toma de Merleau-Ponty es que el significado de la obra de arte no reside en el cielo de las ideas. No subsiste en la eternidad a la manera de una idea. Nos remite a la afirmación de Merleau-Ponty: "En un cuadro o en una pieza musical, la idea solo puede comunicarse por el despliegue de los colores y los sonidos" (Merleau-Ponty, 1945:186). 
Guerrero analiza la composición como una constelación de cualidades sensibles que no existen previamente a su configuración artística ni independientemente unas de otras sino en la totalidad sensible que se manifiesta en la misma obra. La visión, la audición, el tacto, etc. ya están habitados por un sentido que les da una función en el espectáculo del mundo y en nuestra existencia. Nos recuerda la afirmación de Merleau-Ponty en el capítulo sobre "El campo fenoménico" en la Fenomenología de la percepción:

La visión está ya habitada por un sentido que le da una función en el espectáculo del mundo como en nuestra existencia. El puro quale solo nos será dado si el mundo fuera un espectáculo y el cuerpo propio un mecanismo del que un espíritu imparcial tomara conocimiento. Por el contrario, el sentir inviste a la cualidad de un valor vital, la aprehende en primer lugar en una significación para nosotros, [...] El sentir es esta comunicación vital con el mundo que nos lo hace presente como lugar familiar de nuestra vida (Merleau-Ponty, 1945: 64 ss.).

Guerrero subraya que el sentido que habita por igual en la obra y en nosotros dota a la cualidad de un valor existencial en virtud del cual siempre la captamos en su significado para nosotros. Por tanto, el ámbito de las cualidades sensibles es una comunicación vital con el mundo en general y con el mundo del arte en particular. Estos mundos quedan convertidos por la comunicación vital en lugares de encuentro y de trato, de un encuentro y un trato más familiar en el caso del mundo en general, y más descomunal en el caso del mundo del arte. La obra presente y el comportamiento acogedor deben a este tejido sensible su mutua afinidad. La cualidad sensible de una obra de arte es la sugestión que nos llega y a la cual respondemos en tanto disponemos de campos sensoriales adecuados. Es la sugestión silenciosa de una cierta manera de existir. En palabras de Merleau-Ponty: “Las sensaciones, las 'cualidades sensibles', están, pues, lejos de reducirse a la experiencia de un cierto estado o de un cierto quale indecible, ellas se ofrecen con una fisonomía motriz, ellas están envueltas con una significación vital" (Merleau-Ponty, 1945: 242). Así, dice Guerrero, todo quale forma parte de una composición que dirige un llamado, bajo variadas especies de significación, a alguien cuyo modo de ser consiste en tomar posición en el mundo del arte acogiendo ese llamado. Toda cualidad está inscripta en la obra misma, y a la vez insertada en una actitud de revelación y acogimiento. Las significaciones que nos ofrece la composición artística solo se llenan al encuentro de la invitación ofrecida por la obra y la respuesta que recibe de parte nuestra. La composición se constituye únicamente en ese lugar de acuerdo entre la especificidad de la solicitud y la especificidad del recibimiento.

El ser humano inventa y elabora inéditas actitudes de respuesta para los significados que las cosas mismas le proponen. En la experiencia más simple encontramos esta dialéctica que hace que encontremos una afinidad de base entre las cosas y nuestra propia existencia. Por esta razón no solo somos afectados por las cosas sino que nos volcamos afectivamente hacia ellas y elaboramos un bosquejo de la cosa. En un segundo paso elaboramos un bosquejo del mundo al pasar de una perspectiva local de los entes a perspectivas más amplias hasta llegar al esquema general del mundo como una dialéctica de entes presentes y ausentes. Guerrero aplica esta dialéctica a las configuraciones primaria y secundaria de la obra de arte. En un primer momento experienciamos una secreta afinidad con la riqueza sensual de la obra y logramos una coincidencia de nuestro temple de ánimo con la presencia más carnal de la obra. Pero en un segundo momento captamos la obra con más plenitud por medio de la conquista de otras perspectivas cada vez más amplias que nos permiten alcanzar el mundo como ese fondo originario que, implícito de antemano, se va explicitando en nuestro trato con la obra de arte. Aun en nuestro trato con la configuración primaria, en sus aspectos más directos e inmediatos, siempre tenemos latente la presencia virtual del mundo al que pertenecen esas cualidades sensoriales. El mundo es el horizonte sobre el que esas cualidades pueden destacarse. 
Guerrero analiza la obra de arte como apertura de posibilidades. Remite a MerleauPonty para quien la más humilde de las percepciones ya incluye una gran variedad de ingredientes imaginarios, y quien quisiera reducir el campo perceptivo a los factores apegados a la realidad quedaría desterrado al más irreal de todos los mundos (cfr. Merleau-Ponty, 1945: 345 ss.). Guerrero señala que las imágenes cumplen una tarea previa y primordial porque abren el camino de las percepciones y hacen posible el funcionamiento de la actividad perceptiva en sentido estricto. Siempre vamos a lo real por lo irreal. La imaginación es una postura de posibilidades irreales, pero realizables. De modo que enriquece la realidad en dimensiones posibles. La imaginación es la alteridad de una realidad preestablecida, pero también hace perceptible una nueva figura posible de la realidad.

Según Guerrero, la elaboración consciente de un estilo, es decir, el hecho de que un espectador contribuya al advenimiento estilístico de una obra de arte y, por tanto, penetre en sus intenciones, las continúe, y realice así una tarea histórica, es siempre un proyecto artístico concreto, elaborado por los hombres dentro de una particular orientación cultural. Esto significa que el otorgamiento de un significado estilístico a una obra o a un cierto grupo de obras de arte se produce siempre en una específica dirección histórica encaminada hacia un futuro o "por-venir" artístico que se elabora dentro de la coexistencia social, pero sobre la base de una convivencia histórica y, por tanto, sobre la base de tradiciones culturales que gravitan sobre artistas y contempladores por igual. Esto implica, según lo puso de relieve Merleau-Ponty, un anonimato social anterior a todas nuestras decisiones personales.

Guerrero llama estilo a un poder de advenimiento que caracteriza a la obra de arte como tal. Con ello presuponemos, por un lado, obras autónomas, capaces de presentarse por sí mismas y defenderse por sí solas, y, por otro, contempladores capaces de captar a través de esas obras las líneas de los avances y retrocesos de una marcha de la historia. Y subraya que el estilo no es exclusivamente una manera de arrancar las cosas al mundo de los hombres para darles un nuevo significado en el mundo del arte, sino que también se nos revela en la manera original de estar en el mundo de cada hombre y de cada época, pueblo y cultura. Es un índice de libertad en la manera de tratar con las cosas, de sentirlas, y de quererlas. Este índice de libertad se manifiesta en la manera de realizar todo trabajo y en la estructura de toda obra producida por el hombre. Guerrero glosa casi literalmente la siguiente afirmación de "El lenguaje indirecto y las voces del silencio" sobre el estilo:

Es necesario verlo aparecer en el hueco de la percepción del pintor como pintor: es una exigencia surgida de ella. Malraux lo dice en uno de sus mejores pasajes: la percepción ya estiliza. Una mujer que pasa no es en primer lugar para mí un contorno corporal, un maniquí coloreado, un espectáculo, sino que es 'una expresión individual, sentimental, sensual', es una cierta manera de ser carne dada toda entera en la marcha o incluso solo en el choque del taco contra el suelo, como la tensión del arco está presente en cada fibra de la madera - una variación muy notable de una norma de marchar, de mirar, de tocar, de hablar que poseo ante mí porque soy cuerpo (Merleau-Ponty, 2000: 67 ss.).

Ahora bien, si el estilo se nos revela en una manera de estar en el mundo, Guerrero sugiere completar el planteo de Merleau-Ponty. La percepción estiliza porque antes hemos introducido una norma estilística en las acciones y las obras de los hombres. Por tanto, la norma estilística no proviene de un ámbito natural o ingenuo de la percepción sino de una manera de habitar el mundo. La norma estilística es puesta en obra por la capacidad del artista: "Picasso no 'representa', ni 'estiliza' mujeres reales, pero las mujeres de nuestro tiempo se conducen, cada vez más, de acuerdo con los criterios estilísticos de las corriente de arte traídas por el cubismo" (Guerrero, 1956a: 
409). Así, Guerrero considera que tal o cual mujer puede caber en un cuadro en tanto se expone en esa obra un mundo donde resulta posible esa particular manera de ser mujer. El cuadro expone una manera de habitar el mundo, de interpretar el mundo por la mirada y el ademán corporal. Con otras palabras, nuestro mundo humano le ofrece al pintor, al escultor y al novelista los ingredientes para elaborar un estilo, y la obra de arte original devuelve esos ingredientes transfigurados en estilo.

El segundo tomo de la obra de Guerrero está dedicado a la estética de las potencias artísticas, es decir, a la creación y ejecución de la obra de arte. El autor nos recuerda lo que Merleau-Ponty afirma en su capítulo de la Fenomenología de la percepción sobre "El otro y el mundo humano":

Es necesario redescubrir, junto al mundo natural, el mundo social, no como objeto o suma de objetos, sino como campo permanente o dimensión de la existencia: [...] Nos es necesario volver a lo social como aquello con lo cual estamos en contacto por el solo hecho de que existimos, y que llevamos adosado a nosotros antes de toda objetivación (Merleau-Ponty, 1945: 415).

Guerrero subraya que nos encontramos en un mundo circundante antes de imprimir un rumbo más específico a nuestras actividades particulares. Esta coexistencia o ser en común con los prójimos, las cosas y el mundo dentro de una tradición cultural sirve de apoyo a los comportamientos más elevados. Solo en virtud de esta experiencia no-objetiva de convivencia y comprensión mutuas, el artista puede responder a los llamados de la tradición cultural y el contemplador puede acoger los llamados de una obra de arte. Esta comunicación se realiza a través de sucesivos sedimentos históricos y culturales, pero siempre a partir del más limitado horizonte de nuestra época, sociedad y cultura. Solo es posible si descubrimos en nuestra propia vida y época las estructuras fundamentales de la historia. Lo social, lo cultural y lo histórico no existen originariamente como objetos sino que son elaboraciones de ciertos modos concretos de co-existencia humana.

Las cualidades artísticas más particulares y aislables irradian de un cierto modo de existencia y nos invitan a una convivencia de sentido anterior a los significados objetivos que podemos elaborar. No hay una cualidad invariable sino algo ya conocido ciegamente por la familiaridad de nuestro cuerpo y la habitualidad de una tradición social. Merleau-Ponty escribe:

Así, antes de ser un espectáculo objetivo, la cualidad se deja reconocer por un tipo de comportamiento que la intenciona y es por ello que, desde que mi cuerpo adopta la actitud del azul, obtengo una cuasi-presencia del azul. No hay que preguntarse, pues, cómo y por qué el rojo significa el esfuerzo y la violencia, y el verde el reposo y la paz, es necesario volver a aprender a vivir estos colores como los vive nuestro cuerpo, es decir, como concreciones de la paz o de la violencia (Merleau-Ponty, 1945: 245).

Guerrero comenta que debemos reaprender a vivir tales colores como los vivieron nuestros antepasados dentro de una tradición artística, es decir, por una participación mágica en un simbolismo tradicional. Sobre la base de la sedimentación histórica entendida como convivencia templadaza, el azul es un color que solicita una cierta manera de mirarlo en el acogimiento, de ejecutarlo o de requerirlo según las tres direcciones de la estética operatoria. En la estética productiva, el azul es un cierto campo, atmósfera o espacio que se ofrece a la potencia inspiradora del artista creador.

Merleau-Ponty observa que la pintura de Cézanne es un ensayo para reunir la fisonomía de las cosas y los rostros por medio de la restauración integral de la configuración 
sensible de ambos (cfr. Merleau-Ponty, 1945: 372 ss.). Guerrero añade que esto solo se logra en la ejecución de un proceso creador. El creador o ejecutor modula el cuerpo propio de la obra hasta conferirle una existencia capaz de mostrarse por sí misma con lo cual la instala en el mundo exterior como una cosa perceptible y accesible a todos.

La Estética culmina con un tomo dedicado a las tareas artísticas. Este dominio no es protagonizado por los contempladores ni por los creadores, sino por los hombres anónimos de un conglomerado cultural que "piden al arte la premonición de sus esperanzas y la rememoración de sus glorias" (Guerrero, 1967: 16). Al señalar que las "máximas figuras de la filosofía actual" apelan al arte para explicar la situación actual, menciona los "apretados ensayos de Merleau-Ponty" junto a M. Heidegger, J.-P. Sartre y K. Jaspers (Guerrero, 1967: 32, 49). El artista creador recibe un reclamo impersonal, una suerte de obra pro-puesta que señala de antemano el camino a la propia puesta en obra. Un coro de voces humanas actúa silenciosamente en el fondo de la creación. Demandas imperiosas de una sociedad y una época deben ser traducidas al lenguaje del arte. Se promueven tareas artísticas en virtud de una disponibilidad de la comunidad. Esta entonación histórico-social del arte requiere una transposición de la vida en el plano imaginario, un espectáculo de la vida total del hombre, que introduce un análisis del juego y el festival. Aquí Guerrero sigue lo que denomina "un luminoso planteo de Merleau-Ponty" (Guerrero, 1967: 80) en La estructura del comportamiento según el cual el comportamiento y, por tanto, el juego pueden ser vividos como comportamiento sincrético, comportamiento a-movible y comportamiento simbólico.

En el plano sincrético, el individuo que juega vive en una libertad totalmente irreflexiva. Sus comportamientos están presididos por una totalidad perceptivo-motoraafectiva. Y juega con objetos que constituyen una amalgama inestable de sentidos diversos, carecen de un nexo definido con el resto del mundo, y, articulados en distintos contextos, no son los mismos objetos. El mundo carece de una estructura coherente y estable, de modo que el trato con el mundo es un diálogo lleno de sorpresas y mutaciones. En el plano a-movible, se despliega un comportamiento más estable que implica esfuerzo y aprendizaje y pierde su carácter imprevisible. Ingresamos en la esfera de los hábitos, y las situaciones se estructuran con mayor claridad. El individuo ya no vive de un modo totalmente irreflexivo, sino que toma conciencia de sí mismo y experimenta el placer de crear sus imágenes y sus reglas y de someterse a ellas de modo que accede a un plano lúdico a-movible. Por último, en el plano simbólico, emerge una conciencia reflexiva de la libertad. Ya no se juega con objetos dados sino que se los crea de modo que el hombre se hace capaz de generar mundos culturales. Sobre esta base ofrecida por Merleau-Ponty, Guerrero efectúa un análisis del festival cuyo rasgo distintivo es ser el gran juego de un pueblo histórico y el lugar originario de reunión de todas sus tareas artísticas. Aunque en apariencia real, la fiesta está profundamente arraigada en lo imaginario. Es una perfección actual y operante de la vida humana y a la vez su transposición simbólica o imaginaria.

La comunidad no solo realiza una tarea de celebración, sino que promueve y requiere una elaboración que el arte convierte en excelencia consumada. Así, una tarea comunitaria de conducción se orienta, dentro de una tradición cultural, a conservar y renovar la marcha de un estilo. Al ocuparse de las intenciones libres y los sedimentos tradicionales en la propagación de las obras artísticas, Guerrero remite a la afirmación merleau-pontyana sobre "un pacto más antiguo sellado entre $\mathrm{X}$ y el mundo en general". (Merleau-Ponty, 1945: 293). Merleau-Ponty alude a que mi historia es la continuación de una prehistoria porque utiliza los resultados adquiridos por esta. Y Guerrero subraya que el pacto es retomado y al mismo tiempo renovado "porque lo cumplimos conduciéndolo por nuestro propio camino" (Guerrero, 1967: 201; cfr. 215). La constitución de un nuevo nivel en la sensibilidad estética siempre supone un 
nivel dado. Viejas configuraciones artísticas son sometidas a un poderoso impulso de renovación de tal modo que no solo cambia el sentido de una obra particular sino el sentido del arte en total. Guerrero ejemplifica esta situación en el paso de "El descendimiento de la cruz" de Quentin Metsys, obra pintada hacia 1509, a "La lección de anatomía" de Rembrandt, de 1631-32. Es notable en los dos cuadros la semejanza expresiva entre los rostros que, en un caso, convergen sobre el cuerpo de Cristo, y, en el otro, sobre el cadáver que es objeto de la lección. Pero los mundos son distintos. Así, la primera obra opera como trastienda estilística de la segunda en el pasaje de un mundo presecularizado al moderno mundo del naturalismo técnico-científico.

La elaboración debe tener en cuenta que la obra de arte es una modulación de nuestra propia existencia, y que la existencia humana es una coordinación dialéctica de planos. Guerrero vuelve sobre el tema de que la producción de una obra de arte tiene que arrancar de una interpretación existencial porque es una operación existencial. Refiriéndose a Merleau-Ponty (cfr. Merleau-Ponty, 1945: 176), introduce el tema del cuerpo propio:

La obra de arte es más bien comparable al cuerpo propio: es un nudo de significaciones donde la expresión y lo expresado se unifican. Es un sentido accesible directamente, pero que también irradia significaciones multivalentes sin perder su lugar espacial y temporal. [...] La obra de arte es, así, más que una fabricación, una modulación de nuestra propia existencia. Se explica, precisamente, la relación entre su 'estrato instrumental' y su 'estrato valioso', porque la misma experiencia humana es una coordinación dialéctica de 'módulos' o 'planos'. Y en ambas, la relación entre un orden inferior y un orden superior es la de lo parcial a lo total. Por eso la aparición de órdenes superiores suprime como autónomos a los inferiores y da a los acontecimientos una significación nueva (Guerrero, 1967: 135; cfr. 138). 


\section{Bibliografía}

"Berger, G. (1950). L'homme et ses limites. Actas del Primer Congreso Nacional de Filosofía. Mendoza: Universidad Nacional de Cuyo.

»Ceriotto, C. L. (1964). Lenguaje y reflexión según Merleau-Ponty. Philosophia, 29, 50-58.

»Ceriotto, C. L. (1969) Fenomenología y psicoanálisis. Aproximación fenomenológica a la obra de Freud. Buenos Aires: Troquel.

" Dagfal, A. (2011-2012). Luis María Ravagnan: Psicología y filosofía: Del Bergsonismo a la filosofía existencial. Revista de Psicología 12, 71-107.

»Guerrero, L. J. (1956a). Estética operatoria en sus tres direcciones. I) Revelación y acogimiento de la obra de arte. Estética de las manifestaciones artísticas. Buenos Aires: Losada.

》Guerrero, L. J. (1956b). Estética operatoria en sus tres direcciones. II) Creación y ejecución de la obra de arte. Estética de las potencias artísticas. Buenos Aires: Losada.

》Guerrero, L. J. (1967). Estética operatoria en sus tres direcciones. III) Promoción y requerimiento de la obra de arte. Estética de las tareas artísticas. Buenos Ares: Losada.

» Merleau-Ponty, M. (1945). Phénoménologie de la perception. Paris: Gallimard.

" Merleau-Ponty, M. (1960). Signes. Paris: Gallimard.

" Merleau-Ponty, M. (2000). Parcours deux 1951-1961. Lagrasse: Verdier.

» Ravagnan, L. M. (1952). La unidad psicofísica. Monografías psicológicas (Buenos Aires: Universidad de Buenos Aires), 7.

» Ravagnan, L. M. (1957). Maurice Merleau-Ponty: La Structure du comportement. Revista de Educación 6, 610-614.

» Ravagnan L. M. (1958). Acerca del esquema corporal. Revista de Educación 10, 6670.

» Ravagnan, L. M (1958). Problemas psicológicos contemporáneos. Buenos Aires: Nova.

"Ravagnan, L. M. (1959). Maurice Merleau-Ponty y la psicología fenomenológica. Buenos Aires. La Nación, 29-III-1959.

»Ravagnan, L. M. (1967). Merleau-Ponty. Buenos Aires: Centro Editor de América Latina.

» Ravagnan, L. M. (1969). Psicología existencial. Buenos Aires: Nova.

» Ravagnan, L. M. (1974). La psicología fenomenológica: Maurice Merleau-Ponty. Buenos Aires: Paidós.

"Walton, R. J. (1970). Merleau-Ponty y el problema del tiempo. Cuadernos de Filosofía 13, 77-98. 
